Se a mãe faz a opção pelo parto domiciliar, ela necessita comprar uma caixa (PACKAGE) com todos os utensílios necessários ao trabalho de parto (kit for baby), como bandagens, modess, fraldas descartáveis. O custo dessa caixa é de 57 florins (30 dólares) e, é reembolsado pelo seguro saúde. Essa caixa é vendida nas lojas especializadas em assistência à saúde que se situam próximas aos Centros de Saúde (Consultait Bureau). Estas lojas vendem, emprestam ou alugam cadeira de rodas, cadeira para banho, muletas e carros para locomoção de idosos, camas hospitalares, bombas de ordenha mamária, bicos especiais de mamadeira e sutiã para amamentar. Alguns itens são emprestados ao paciente por 6 meses e outros são vendidos; mas o seguro saúde, público e/ou privado, cobre todas as despesas de assistência, incluindo a medicação.

A obstetriz presta um serviço a gestante que inclui um conjunto de procedimentos: pré-natal (uma consulta/mês ao casal), assistência ao parto e pós-parto. Esse pacote de prestação de serviços tem um custo de 1.080 guilders florins (500 dólares) à gestante, que é reembolsado pelo sistema nacional de saúde ou seguro saúde privado.

\section{FORMAÇÃO DA OBSTETRIZ}

É um curso destinado à formação de obstetrizes e tem a duração de 4 anos, e não estabelece relações durante a formação com o curso de enfermagem, bem como há associações de profissionais distintas. A formação é centrada na saúde e não na doença, reafirmando que o pré-natal e a assistência ao parto e pós-parto é um período saudável da mulher, e não deve ser medicalizado.

A Associação de obstetrizes da Holanda é uma das mais organizadas do mundo e submete os profissionais a avaliações freqüentes. Essa associação recebe obstetrizes do mundo inteiro para treinamento.

A obstetriz desenvolve uma prática independente em consultório particular, podendo atender em diferentes locais. Ela pode alugar uma sala no Centro de Saúde (consultait bureau), ou atender na sua própria residência.

\title{
MANUSEIO E PREPARO DE QUIMIOTERÁPICOS: UMA COLABORAÇÃO AO PROCESSO REFLEXIVO DA CONDUTA DA ENFERMAGEM
}

\author{
Ana Beatriz Carvalho Monteiro* \\ Maria das Graças de Paiva Nicolete** \\ Maria Helena Palucci Marziale*** \\ Maria Lúcia do Carmo Cruz Robazzi****
}

O presente artigo aborda a questão da biossegurança no manuseio dos quimioterápicos, especificamente os antineoplásicos pela equipe de enfermagem.

Embora existam recomendações e normas estabelecidas pelo Conselho Federal de Enfermagem, órgão que regulamenta a prática da Enfermagem no Brasil (BRASIL, 1995) e pelo Instituto Nacional do Cancêr, muitos profissionais de Enfermagem não adotam as medidas necessárias para o manuseio e preparo de quimioterápicos, o que tem lhes ocasionado sérios problemas de saúde.

Segundo ALMEIDA (1998) o desrespeito as referidas normas parece estar mais relacionado à falta de disponibilidade de recursos materiais e às falhas organizacionais das unidades hospitalares do que ao nível de conhecimento, de desinteresse e/ou ao desestímulo dos profissionais de enfermagem.

Com o objetivo de estimular a reflexão sobre os riscos que a equipe de enfermagem está exposta ao manipular os quimioterápicos antineoplásicos; fornecer subsídios para ampliar os conhecimentos em relação a temática e vislumbrando chamar atenção para a necessidade de adequação das condições de trabalho oferecidas, principalmente nos hospitais, nos motivamos escrever este levantamento documental,

* Mestranda em Enfermagem Fundamental da Escola de Enfermagem de Ribeirão Preto da Universidade de São Paulo

** Doutoranda em Enfermagem Fundamental da Escola de Enfermagem de Ribeirão Preto da Universidade de São Paulo

*** Professor Doutor do Departamento de Enfermagem Geral e Especializada da Escola de Enfermagem de Ribeirão Preto da Universidade de São Paulo

**** Professor Titular do Departamento de Enfermagem Geral e Especializada da Escola de Enfermagem de Ribeirão Preto da Universidade de São Paulo 
realizado através de técnica de leitura exploratória, interpretativa e seletiva das pesquisas publicadas no Brasil, nos últimos 10 anos, relativas a Biossegurança, Quimioterápicos e Drogas Citostáticas.

Foram utilizadas como fontes bibliográficas, os Index Lilacs, Medline, sendo efetuada ainda pesquisa aos artigos referenciados junto a rede de informações Internet.

A análise dos artigos encontrados se deu através da coleta das seguintes informações; definição de biossegurança, o que são quimioterápicos, como se classificam, aspectos históricos, quais os riscos advindos do preparo, administração e descartes de quimioterápicos pela equipe de enfermagem e aspectos legais do manuseio de quimioterápicos no Brasil.

Através das pesquisas descritas na literatura podemos apreender que o termo Biossegurança relacionado aos quimioterápicos e a enfermagem é pouco utilizado. Biossegurança pode ser entendida como, aquela que envolve além do risco biológico, aqueles periféricos, ou seja, os riscos químicos, físicos e fatores ergonômicos.

Os riscos químicos constituem um importante fator predisponente a doenças profissionais e uma ameaça a segurança em muitos ambientes laborais. As substâncias penetram no organismo pelas vias: respiratória, cutânea e digestiva, e exercem sua ação nociva sobre os mais variados sistemas do organismo humano na gênese das doenças profissionais. Dependendo da concentração e do período de exposição ao agente.

Ao descrever sobre estes agentes químicos, BULHÕES (1998) diz que: "são substâncias capazes de produzir todos os tipos de lesão celular, e os efeitos da exposição aos mesmos podem manifestar-se imediata ou tardiamente".

Dentre os vários riscos químicos a que estão expostos os trabalhadores de enfermagem, a manipulação de citostáticos vem merecendo atenção devido a necessidade de observância de medidas de proteção para o preparo e a administração e aos perigos potenciais decorrentes, como o desenvolvimento de neoplasias (BONASSA, 1996).

Um quimioterápico é um composto químico, utilizado no tratamento de doenças causadas por agentes biológicos. Quando aplicada ao câncer, a quimioterapia é chamada de quimioterapia antineoplásica ou antiblástica.

O primeiro quimioterápico antineoplásico comercializável foi desenvolvido a partir do gás mostarda, usado nas duas Guerras Mundiais como arma química. Após, a exposição de soldados a este agente, observou-se que eles desenvolveram hipoplasia medular e linfóide, o que levou ao seu uso no tratamento dos linfomas malignos. A partir da publicação, em 1946, dos estudos clínicos feitos com o gás mostarda a das observações sobre os efeitos do ácido fólico em crianças com leucemias, verificou-se avanço crescente da quimioterapia antineoplásica. Atualmente, quimioterápicos mais ativos e menos tóxicos encontramse disponíveis para uso na prática clínica.

Os quimioterápicos se classificam segundo CLARK \& McGEE (1997), conforme a estrutura química em seus grupos: Alquilantes; Agentes Antimetabólicos; Antibióticos Antitumorais; Nitrosuréias; Alcalóides da Vinca; Agentes Hormonais e Agentes Diversos (miscelânea).

Os perigos potenciais na manipulação e descarte do quimioterápico, de acordo com BONASSA (1996), estão relacionados com danos à diversos órgãos do trabalhador como no fígado, problemas reprodutivos, tais como aumento da incidência de abortos expontâneos, problemas dermatológicos, vertigens, alergias, náuseas, cefaléia.

Para CLARK \& McGEE (1997) a exposição aos agentes antineoplásicos ocorre por contato direto (pele, membranas, mucosas ou por inalação ) e indiretos (fluídos corporais e excretas de clientes nas últimas 72 horas que receberam a medicação). Os efeitos podem ser imediatos (dermatite, hiperpigmentação da pele e outros) e tardio (alopecia parcial, anormalidade cromossomas e aumento do risco de desenvolver câncer).

Em relação aos aspectos legais no Brasil encontramos os seguintes documentos: Resolução $\mathrm{n}^{\circ} 5$ de 5/08/1993, do Conselho Nacional de Meio Ambiente, que trata de normas mínimas sobre o tratamento de resíduos sólidos. Portaria MS/GM, no 3535 de 02/09/ 1998, que estabelece critérios para cadastramento de centros de atendimento de oncologia (BRASIL, 1998).

Resolução do COFEN - 210/98, que dispõe sobre a atuação dos profissionais de enfermagem que trabalham com quimioterápicos antineoplásicos (BRASIL. CONFEN, 1998).

Visando à proteção ambiental e pessoal nos locais de trabalho estabeleceram-se diretrizes para manipulação segura de quimioterápicos. O manual de normas técnicas administrativas do Instituto Nacional do Câncer, do Ministério da Saúde destaca dentre outros, aspectos importantes, tais como a necessidade do preparo centralizado, capela de fluxo laminar vertical classe II, paramentação adequada, avaliação médica periódica do pessoal envolvido, cuidados com a administração e descarte de materiais; programas de capacitação técnica e reciclagem, enfatizando aspectos relacionados com os riscos ocupacionais e normas para reduzir contaminação. 


\section{CONSIDERAÇÕES FINAIS}

Embora na literatura encontramos autores que apontam a falta de recursos materiais como causa de manipulação inadequada de quimioterápicos pelos profissionais de enfermagem, nossa vivência prática em hospitais nos leva a acreditar que a falta de conhecimento em relação aos riscos provenientes da referida atividade entre os trabalhadores de enfermagem, tem oportunizado negligência em relação a normalização preconizada e necessária a segurança do trabalhador de enfermagem na execução de suas atividades laborais.

Os quimioterápicos antineoplásicos

\section{REFERÊNCIAS BIBLIOGRÁFICAS}

01. ALMEIDA, T.M.da S. Segurança ocupacional da equipe de enfermagem no preparo de citostáticos endovenosos. Hospitais do Recife

- PE, Salvador, 1998. 111 p. Dissertação (Mestrado) - Escola de Enfermagem, Universidade Federal da Bahia.

02. BRASIL, Portaria $\mathrm{n}^{\mathrm{o}} 3535$ de 02 de setembro de 1998. Estabelece critérios para cadastramento de centros de atendimento em oncologia. Diário Oficial da União, Brasília, 02 de setembro de 1998.

03. BRASIL. Recomendações sobre a segurança do manuseio e preparo de drogas citostáticas pela equipe de enfermagem. Bol.COFEN., s.n.t. p. 19-22. 1995. /fotocópia/ representam um risco potencial para quem prepara, administra e descarta, devido a absorção do produto pelas vias respiratórias, mucosas e cutânea.

A equipe de enfermagem vem manipulando quimioterápicos há anos em condições inseguras e necessita urgentemente da adoção de medidas para reverter tal situação.

Os recursos legais existentes no Brasil sobre manuseio de quimioterápicos são recentes e não tem ainda o conhecimento por parte de quem prepara, administra ou descarta, o que não assegura, o direito necessário a melhoria das condições de trabalho.

04. BRASIL. Resolução COFEN nº 210 de s.m. de 1998. Dispõe sobre a atuação dos profissionais de enfermagem que trabalham com quimioterápicos antineoplásicos dentro das normas de biossegurança estabelecidas pelo Ministério da Saúde conforme Portaria n. 170/ SAS. Bol.COFEN., s.n., s.p. 1998. /fotocópia/ 05.BONASSA, E.M.A. Enfermagem em quimioterapia. São Paulo: Atheneu, 1996. $279 \mathrm{p}$.

06. BULHÕES, I. Riscos do trabalho de enfermagem. Rio de Janeiro, s.d., 1998. 221 p.

07. CLARK, J.C.; McGEE, R.F. Enfermagem oncológica: um curriculum básico. 2 ed. Trad. De Luciane Kalakum e Luiza Maria Gerhardt Porto Alegre: Artes Médicas, 1997. 586 p.

08. QUIMIOTERAPIA [on-line][citado em $14 \mathrm{de} \mathrm{dez}$ de 1998]. Disponível: http://www.inca.org.br/ tratamento/quimioterapia.html

\section{CONDIÇÕES CRÔNICAS DE SAÚDE E O CUIDADO DE ENFERMAGEM}

Maria Célia de Freitas* Maria Manuela Rino Mendes**

Nos dias atuais, o binômio saúde e doença não têm sido centrado, unicamente, nos aspectos biológicos, mas sim relacionados às características de cada sociedade, onde tanto a concepção de saúde e doença quanto o doente são considerados dentro do contexto social (MINAYO 1991, p.233).

O processo de construção do conhecimento e seus recentes avanços tecnológicos e científicos sobre

* Professor da Universidade Estadual do Ceará. Pós-graduanda de Mestrado em Enfermagem Fundamental da Escola de Enfermagem de Ribeirão Preto da Universidade de São Paulo

**Orientador. Professor Doutor do Departamento de Enfermagem Geral e Especializada da Escola de Enfermagem de Ribeirão Preto da Universidade de São Paulo 